\title{
Community-Level Prevention of Childhood Maltreatment: Next Steps in a World with COVID-19
}

\author{
Beth E. Molnar ${ }^{1}$ (D) Arielle A. J. Scoglio ${ }^{1}$ (D) - William R. Beardslee ${ }^{2}$ (D) \\ Accepted: 27 November 2020 / Published online: 6 January 2021 \\ (C) The Author(s), under exclusive licence to Springer Nature Switzerland AG part of Springer Nature 2021
}

\begin{abstract}
Maltreatment of children continues to be a major public health concern, with high social, economic and health burdens. Rates vary by a number of factors that can be categorized into different levels of the social ecology. Research and theory in this field point to the importance of community-level factors that can contribute to either risk or prevention of child maltreatment. The COVID-19 pandemic context creates additional risks and concerns related to child maltreatment and exacerbates risk factors that existed before: e.g., families and communities are in much worsened states of poverty, unemployment, and food insecurity; losses and grief are affecting mental health; and limitations and safety concerns are affecting inperson child protection work and more. Central to recovery from this pandemic will be the mobilization of community-level resources and the building back up of the social fabric that can support vulnerable children and caregivers. Key to this mobilization will be a better intersectional understanding of structural inequities in the child welfare system and in our communities. Efforts to dismantle structural biases and discrimination are critical to provide safety and support for families and vital for effective child maltreatment prevention. In this context, we discuss the state of the science of community-level prevention of childhood maltreatment, highlighting evidence-based community-level prevention programs and how these types of efforts may be impacted by the current COVID-19 global pandemic.
\end{abstract}

Keywords Child maltreatment · Community-level $\cdot$ Prevention $\cdot$ COVID

Beth E. Molnar

b.molnar@northeastern.edu

1 Bouvé College of Health Sciences, Northeastern University, 360 Huntington Ave, M/S INV 314, Boston, MA 02115, USA

2 Department of Psychiatry, Boston Children's Hospital, 300 Longwood Avenue, Boston, MA 02115, USA 
Maltreatment of children is an ongoing and global public health concern. Estimations from the World Health Organization suggest that more than a billion children experienced maltreatment globally in the past year, based primarily on data from the global North (Hillis et al. 2016). In the USA, 1 in 4 children is estimated to be affected by child maltreatment (Finkelhor et al. 2013). The term "child maltreatment" encompasses a range of adverse experiences in childhood, including physical, sexual, or emotional abuse and neglect. These early life experiences have been linked to a myriad of longterm physical and mental health consequences (Carr et al. 2020; Lanius et al. 2010). Negative mental health outcomes linked to childhood maltreatment include posttraumatic stress disorder, substance misuse, depression, and suicide attempts (Dube et al. 2001; Greene et al. 2016; Molnar et al. 2001a, b; Norman et al. 2012; Walsh et al. 2007). Physical health consequences associated with childhood maltreatment include physical injury, mortality, and increased risk for multiple chronic health conditions (Carr et al. 2020). In addition to the negative health consequences experienced by individuals, research has shown us that families and communities suffer as well. The economic burden of childhood maltreatment in the USA before the COVID-19 pandemic was estimated in the trillions of dollars each year (Peterson et al. 2018).

Currently, we are in the midst of a global pandemic with uncertainty as to when and if our previous social structures, service delivery systems, and prevention efforts will return to "normal." It is important to acknowledge that closure of schools represents a decline in available trauma-informed supports and care for children (Phelps and Sperry 2020); Hoffman and Miller 2020). Staying home from school also means more limited access to mandated reporters, and so maltreatment may be more difficult to recognize (Cohen and Bosk 2020). A rapid review of the literature on the psychological impact of quarantine found many short- and long-term effects (Brooks et al. 2020). Research shows that rates of child abuse and neglect tend to increase during and immediately following disasters (Schneider et al. 2017), but also that their impacts may be ameliorated by parental support (Sprague et al. 2015). The mandated lockdowns and increased economic strain across much of the globe are concerning to child maltreatment professionals, expecting that the school closures, restrictions, stress, and additional time in homes with caregivers who are abusive are heightening risk factors in populations that are already vulnerable (Abramson 2020; Hoffman and Miller 2020; Nay 2020). Early reports suggest that children that are in the care of child welfare systems are either being returned to families of origin before the work is completed to address the concerns that had them removed or they are not being visited by case workers if they are still at home and were deemed in need of monitoring (Goldman et al. 2020; Wilke et al. 2020).

Soon after the COVID-19 pandemic was recognized as spreading in the USA, substantial drops in childhood maltreatment official reports were noted by US states across the nation (Axios 2020; Stout 2020). Child protection officials reported to journalists that this decrease was simultaneously accompanied by an increased severity in cases that were being reported, though data on this report was not yet available (Venkatraman 2020). In addition, a national child abuse hotline (Childhelp) reported substantial increases in the frequency of calls and texts received (Venkatraman 2020). A recent study examined monthly data on child maltreatment allegations in New York City and found substantially fewer reports than expected for March, April, and May of 2020 (Rapoport et al. 2020). This was true for all reporter types and was related to 
fewer investigations that included preventative services than would be expected. The authors urge educators and healthcare workers to pay special attention, even in online interactions, to signs of child abuse or neglect.

Child maltreatment rates vary by a number of factors from different levels of the social ecology (Bronfenbrenner 2005). Historically, individual-level factors, such as the sex and age of a child, have been tied to differences in rates. Family-level risk factors are also critically important, including substance use of caregivers, mental illness, intimate partner violence, and low socioeconomic status - the latter including living in poverty, being unemployed, and experiencing food insecurity (Drake and JonsonReid 2014; Dube et al. 2001; Sedlak et al. 2010).

Over time, childhood maltreatment research and prevention efforts have expanded to include community-level factors and community-based responses as well, frequently grounded in Bronfenbrenner's Bioecological Theory of Human Development (1979, 2005). This theory posits that the many contexts of influence where individuals spend time can be conceptualized as systems and that both promotive factors and risk factors can occur in those systems. Changes in one system can influence changes in another, and such influences may be bidirectional. Studies have identified positive neighborhood social processes such as collective efficacy and social network size that are associated with lower rates of child maltreatment (Abdullah et al. 2020; Freisthler and Maguire-Jack 2015; Kimbrough-Melton and Melton 2015; Molnar et al. 2003; Molnar et al. 2016b). For example, Molnar et al. (2016a) examined 11 years of substantiated reports of child maltreatment in Chicago, Illinois, and found that collective efficacy, intergenerational closure and larger social networks were each associated with lower maltreatment rates at the neighborhood level (Molnar et al. 2016b). McLeigh et al. (2018) found that social cohesion mediated the association between neighborhood-level poverty and child abuse rates, though not neglect rates. In 2007, Coulton and colleagues put both structural factors and social factors that occur in neighborhoods into one model of the social ecology of child maltreatment (Coulton et al. 2007). In this combined model, neighborhood social processes such as informal social control are influenced by structural factors such as neighborhood economic disadvantage as well as able to act as a buffer to the influences of material hardship and exposure to violence. Rates of child maltreatment depend on the balance of positive and negative community-level characteristics in this model (Coulton et al. 2007). It is at this community level, labeled the exosystem in Bronfenbrenner's work, where community-level prevention is designed to assist. A recent update of this work by Coulton et al. (2018) added evidence of the impacts of neighborhood conditions on child maltreatment by evaluating changes over two decades in investigated child maltreatment reports associated with changes in neighborhood-level structural risk factors (Coulton et al. 2018). Declining employment, increases in single parent families and increases in vacant housing were associated with increases in rates of child maltreatment reports at the census tract level across the 20 years; changes that are happening now during the pandemic. Increased rates of poverty and increased racial diversity were not associated with changes in child maltreatment rates, except in those neighborhoods that transitioned to extreme segregation of Black residents (Coulton et al. 2018). Another recent study sought to identify county-level socioeconomic and crime factors associated with substantiated abuse and neglect rates between 2004 and 2016. They found that abuse and neglect rates were positively associated with teen birth 
rates, percentages of births to unmarried mothers, drug-related offenses, and percentages of children receiving SNAP benefits (Morris et al. 2019). Reviews of the literature on neighborhood characteristics and child maltreatment (Abdullah et al. 2020; Coulton et al. 2007; Freisthler et al. 2006) have identified that structural characteristics of neighborhoods such as low-income levels and high unemployment rates are explanatory factors for increased child maltreatment and that community resources, or social processes such as collective efficacy and social cohesion, are consistently associated with decreased child maltreatment across studies.

The pandemic context of social isolation and increased economic insecurity increases the risk of parental stress and burnout (Griffith 2020; Thompson 2015). Before the pandemic, a systematic review found that across 26 longitudinal studies on the temporal relation between economic security and child maltreatment, income losses, cumulative material hardship, and housing hardship were reliable predictors of child maltreatment (Conrad-Hiebner and Byram 2020). A rapid review of the psychological impacts of quarantine identified a similar list: housing instability, unemployment, financial strain, food insecurity, and health insurance loss (Brooks et al. 2020). Job loss is an important risk factor for child maltreatment and has already been shown as such in the context of the current pandemic (Lawson et al. 2020). A survey of parents conducted during the early months of the shutdown in the Rocky Mountain region of the USA documented that greater COVID-19 stressors were associated with higher child abuse potential scores (Brown et al. 2020). For parents and caregivers who work full time, school closures may increase risk for supervisory neglect (Humphreys et al. 2020). School personnel are the largest source of reports to child protection services and closing schools means a reduction in the ability to detect child maltreatment. In addition, routine and preventative medical care have been postponed for many during the pandemic, in hopes of protecting healthcare system capacity. Unfortunately, this also means that clinicians have fewer chances to detect or prevent child maltreatment (Humphreys et al. 2020). In a community sample of 342 parents, those who had lost their jobs were depressed or had previously psychologically maltreated their children were significantly more likely to physically abuse their children during the pandemic. However, this study found that positive cognitive reframing following job loss moderated the risk of physical abuse (Lawson et al. 2020). Increased stress related to job loss, school closure, or social isolation can all contribute to increased risk of child maltreatment and neglect in the context of this pandemic where the capacity of the child welfare system to protect children is simultaneously impacted.

Another issue that has come much more into the public eye during these pandemic months, coinciding with the uprising in protest of the murder of civilian George Floyd by police officers, is the ubiquity of structural racism in the USA. From the early days of the pandemic, COVID-19 has affected people of color disproportionally in terms of who contracts the virus and who dies compared with whites in the USA (Bassett et al. 2020). Research has documented tremendous structural inequities in the child welfare system and in our communities that contribute to child maltreatment as well (Limber and Kowalski 2020; Manful et al. 2019; Nadan et al. 2015). For example, communities of color are overrepresented in the child welfare system (Drake et al. 2011; Drake and Jonson-Reid 2011; Drake and Rank 2009). Research has identified a number of biases and societal-level inequities that may be determinants of this disproportionality-while early studies focused on the presence of bias and racism in decisions of child welfare 
workers, further research has shown that many risk factors inherent in the resource-poor communities where families of color are disproportionally represented account for many of the differences (Drake et al. 2011; Johnson et al. 2009; Watt and Kim 2019). Distrust of the child welfare system in disadvantaged communities and communities of color, racial bias, or cultural incompetence among decision makers at multiple points in the child welfare system, inequalities in resources that are offered or taken up, and other factors may contribute to the observed disproportionality and disparities (Hill 2006; Johnson et al. 2009; Maguire-Jack et al. 2018; Nadan et al. 2015).Nadan et al. (2015) highlighted the importance of intersectionality in understanding how multiple identities interact at the individual and broader societal levels to influence child maltreatment and shape disparity and disproportionality in child welfare. Intersectionality is a framework that can encourage research, prevention, and intervention work to consider group membership in multiple categories and the ways that treating socially constructed categories (e.g., race) as existing outside of cultural and historical contexts contributes to inequalities in access, service delivery, and outcomes for children and families (Nadan et al. 2015).

In recent years, there has been a shift towards examining how child protection efforts address child neglect (Kobulsky et al. 2019), such as whether systems give enough resources to help families who find themselves in difficult situations, rather than punishing them for circumstances that may be outside their control (e.g., unemployment, health insurance loss). Particularly in the pandemic context, as financial strain and job loss are becoming more prevalent, a revisiting of the definition of maltreatment categories may be indicated to distinguish poverty-related neglect from abuse or endangerment (Weiner et al. 2020). Berman (2020) calls for flexibility and creativity in revising prevention efforts: if community-based initiatives can effectively partner with child protection agencies, they can work together to respond to abuse, but also to promote community-level changes that contribute to child maltreatment prevention (Berman 2020). The replication of the Strong Communities program in Israel (described below) offers insight into one way this might work. In this trial, social work students worked as outreach workers, which improved rapport between social workers and parents in the community and may have long-lasting impacts on these systems and on the social workers and parents themselves (Katz et al. 2019).

Turning to the importance of the community context of the pandemic, social isolation has been identified as a major risk factor for child maltreatment (Limber and Hashima 2002). A related determinant is a lack of community cohesion (Barnhart and Maguire-Jack 2016; Maguire-Jack and Showalter 2016). Pre-pandemic, community-wide efforts were underway to combat social isolation, but in the current pandemic context, a new pro-social norm termed "social distancing" has made it challenging to connect with others in person (Melton and McLeigh 2020). The COVID-19 pandemic is situated in the context of what has been called a loneliness epidemic in the USA, a time when social capital is declining and many individuals feel increasingly isolated from others (Putnam 2000a, b). Child protection service agencies are structured in a way that makes effective change challenging; despite good intentions, these agencies typically do not have the resources to take part in efforts to change community norms - as grassroots initiatives such as Strong Communities (described below) are able to do (Berman 2020). Bureaucratization also sets child protection services apart from community-level prevention efforts, because these agencies are 
currently required to adhere to strict protocols and document all activities (Berman 2020). While isolation can become entrenched, and is linked to multiple negative mental health outcomes, even in this new era of social distancing, individual acts of charity, kindness, and neighborliness are present (Wilke et al. 2020). Whether such acts can be channeled into community-level responses for the common good of eradicating child maltreatment will be seen.

\section{Community-Level Prevention Programs}

A systematic review of the literature on community-level interventions to prevent child maltreatment was conducted in 2016 (Van Dijken et al. 2016). They categorized studies selected in their review according to their definitions of community, based on definitions put forth by McLeroy and colleagues (2003):

(1) Setting: prevention efforts that treat community as defined by geography, and thus it is the behavior of individuals within that area who are reached.

(2) Target: intervening with the whole community as the focus of change, enacting systemic changes in community services or public policies.

(3) Resource: community institutions and members implement health promotion activities or interventions with a sense of community ownership.

(4) Agent: to reinforce existing community capacity and social capital.

They selected five community-level child maltreatment interventions that fell into either the resource or agent categories for their final review. Among these five interventions with evaluation studies, they concluded that while literature has generally accepted the importance of community in prevention efforts, research on the effectiveness of these five interventions was promising but not yet sufficient. The review highlighted the importance of building community capacity and not focusing on problems, as each of these five community-level child maltreatment interventions exemplify. A more recent review of lessons learned from community change programs targeting children and youth (Gross-Manos et al. 2020) found that these programs come from multiple origins, with multiple professional orientations and that programming was most successful when (1) they involved children and not just parents, (2) they included development and empowerment of local leaders, and (3) they promoted community networking towards a goal of cooperation among residents, services, and organizations in the community. In addition, keeping the focus positive was deemed important to keeping children safe, rather than the more stigmatizing focus on maltreatment (Gross-Manos et al. 2020).

\section{Evaluations of Community-Level Prevention Programs}

Since our previous review of community-level programs (Molnar et al. 2016a) and the review cited above (Van Dijken et al. 2016), additional evidence of the efficacy of three community-level prevention programs has emerged. Each include elements that community-level child maltreatment prevention programs typically involve (Molnar 
and Beardslee 2014): (1) programs which work across sectors of a community, (2) programs located community-wide with collaborative input, (3) programs which change community conditions in ways that increase safety and decrease stress on families, and (4) programs which work towards reduction of community-level maltreatment rates. These programs include Triple P, Strong Communities, and the Period of PURPLE Crying. We explore potential challenges and opportunities that these programs may encounter in achieving their goals in the pandemic context.

\section{Triple P-Positive Parenting Program}

Triple $\mathrm{P}$ is a multilevel model of graded reach and intensity of parenting and family support services. The main goal of this program is to prevent behavioral, developmental, and emotional problems in children age $0-16$ by incorporating five levels of intervention for parents. Intervention occurs on a tiered continuum of increasing strength and includes parenting information campaigns (Level 1), brief parenting advice (Level 2), narrow focus skills training (Level 3), broad focus skills training (Level 4), and behavioral family intervention (Level 5). This suite of programming operating on 5 levels offers comprehensive support for parents in the task of raising their children (Sanders 2012; Sanders et al. 2002). The research on Triple $P$ finds continuously positive results and lends support for a blended system of parenting support that includes targeted and universal elements to support families and promote children's healthy development. Effect sizes described across analyses frequently found moderate or large effects. Variability in effect sizes may reflect the multilevel organization of Triple $P$, with interventions of variable intensity which include both prevention and intervention elements (De Graaf et al. 2008; Nowak and Heinrichs 2008; Sanders 2012; Sanders et al. 2014).

In the context of the current pandemic, Triple $\mathrm{P}$ is likely to experience barriers to implementation of levels $2-5$ of their programming. Specifically, in-person meetings, workshops, and training groups are currently discouraged and organizations have had to pivot to move such meetings to an online or virtual format. This shift brings up issues of access: do families and parents involved in skills training and interventions have access to electronic devices, reliable Internet connections, and a quiet private space? It will be important to build upon existing strengths and to identify and promote resiliency in addressing parental stress during and following the pandemic (Lawson et al. 2020). A promising recent study of differences between pre-pandemic in-person training of child protection case workers and post-pandemic virtual training delivery showed that the latter was just as well-received as the former in terms of knowledge gained and satisfaction, demonstrating that successful evolution can happen (Schwab-Reese et al. 2020). Globally, researchers are examining the efficacy of various telehealth approaches that providers rapidly transitioned into when lockdowns began; promising findings are emerging (e.g., Schieltz and Wacker 2020) adding to pre-pandemic systematic reviews on telehealth's utility as a service delivery model (Ferguson et al. 2019; Neely et al. 2017; UnholzBowden et al. 2020) and its acceptability (Tomlinson et al. 2018).

\section{Strong Communities for Children}

Strong Communities for Children was an initiative created in South Carolina in 2002 in response to the US Advisory Board on Child Abuse and Neglect's 1993 
recommendation for the creation of Prevention Zones. The initiative employed a twopronged approach: (1) outreach workers recruited volunteers and engaged community organizations to collaborate to form and implement local action plans to "keep kids safe," and (2) resources generated through the outreach campaign were used in new services for families with young children, using volunteer resources and existing community facilities to help parents increase collective efficacy, build social support networks and provide direct support to families in need (McDonell et al. 2015).

A trial of the effectiveness of Strong Communities showed that both high and lowresource communities where it was implemented experienced declines in child maltreatment for children under the age of 5 (McLeigh et al. 2015). Both types of communities experienced increases in community mobilization, suggesting that community mobilization can be an effective method for prevention even when resources are low. In low-resource settings, the mobilization resulted in significant increases in positive factors such as neighborliness and self-reported positive parenting. In a separate multi-year evaluation of Strong Communities, McDonell et al. (2015) found that compared with non-intervention samples, areas that implemented Strong Communities showed increases in social support, collective efficacy, parental efficacy, child safety in the home, decreases in child maltreatment rates, decreases in child injuries suggesting child maltreatment, and reduced parental stress. Although research evaluating of Strong Communities have been largely confined to its geographic origin (South Carolina, in the southeastern United States), evidence suggests that it is feasible to turn a small economic investment of a small team of outreach workers into growing community-wide change (McLeigh et al. 2020): outreach workers successfully recruited thousands of volunteers and hundreds of organizations to facilitate noticing and caring for families with young children. Changing norms and culture is a difficult challenge, but it occurred in these participating communities, suggesting hope for replication and scaling up of such strategies (Melton and McLeigh 2020). A replication was recently undertaken in Israel, using social work students to conduct outreach and has demonstrated promising preliminary findings (Katz et al. 2019). The founders of Strong Communities suggest that universities may be uniquely suited for sustainable scaling of this programming because relying on students as outreach workers can allow for creative funding strategies and contribute to training of students in multiple majors (Melton and McLeigh 2020).

In the pandemic context, programming that focuses on face-to-face interactions and relationship building faces significant barriers to continued operation. However, many universities are still open and may represent an avenue of community connection and networks in a time when social connection may be difficult to come by. Universities are also resource-rich environments and may be able to help with providing access to virtual offerings and electronic outreach. Connection and intentional outreach, even if virtual, may help to support parents' health and wellbeing as well as to promote healthy coping strategies that may reduce the risk of maltreatment. Strong Communities has shown that broadening of community-based supports to engage whole communities is possible, and these types of programs are especially needed in this difficult time.

Community partner organizations are having to adapt their operations and outreach to fit a socially distant, masked environment. Technical and implementation support may look much different in a pandemic context and focus on maintaining current contacts and outreach efforts, which may be harder to keep up during the pandemic. 
This support may also need to include psychoeducation about the impact of staying at home on children and families and potential increases in risk of violence that accompany a lockdown. Creative solutions in virtual or otherwise socially distanced formats are needed to ensure that community members and mandated reporters are still able to contribute to keeping children safe (Weiner et al. 2020).

\section{Period of PURPLE Crying}

The Period of PURPLE Crying (POPC) initiative was based on an intervention that found education materials led to a $50 \%$ reduction in abusive infant head trauma incidence over 6 years in New York (Dias et al. 2005). It was then expanded by the National Center on Shaken Baby Syndrome and evaluated in multiple sites. Delivery of educational materials has been provided in different ways in different trials of the intervention; it frequently includes an educational booklet, a video, and in-person education provided by a professional, with reinforcement by media campaigns and primary care practices. PURPLE is an acronym for elements of crying in normal infants that may be frustrating to caregivers and could be a potential trigger to shake the infant (Barr 2012): $P$ for peak pattern of crying; $U$ for unexpected crying; $R$ for crying that is resistant to soothing; P for showing a pain-like face when they cry; L for long-lasting cries; and E for evening clustering of crying (Runyan et al. 2009). The educational materials provide strategies for caring for a crying infant, a description of shaken baby syndrome and encourage the sharing of this information with other caregivers. This is an example of a universal prevention strategy being implemented community-wide via distribution by hospitals and/or maternity centers.

In a statewide efficacy study in North Carolina across 91 hospitals, parental calls about crying to the nurse advice line declined significantly after the intervention, but there was no significant reduction in state-level abusive head trauma rates (Zolotor et al. 2015). The statistical power to detect changes in AHT for these evaluation studies is an issue given that abusive head trauma, while devastating when it happens, is quite rare (Barr et al. 2018); thus studies of different outcomes have been implemented. POPC was implemented across British Columbia, Canada with three "doses" provided to each parent of a newborn born over a period of 8 years starting in January, $2008(N=$ over 350,000 parents). They found the program cost-effective, showing that an investment of \$5 US dollars per newborn saved $\$ 14.49$ per child in healthcare costs of abusive head trauma (Beaulieu et al. 2019). They also examined whether hospitalization rates for AHT were reduced after implementation, finding that during the period of time when parents received the program, hospital admission rates for AHT were reduced by $35 \%$ among infants $<24$ months of age (Barr et al. 2018). The intervention is being implemented in rural areas of Queensland, Australia, where a preliminary study showed acceptability among providers (Stephens et al. 2014). In Japan, a small randomized controlled trial was conducted with only the educational materials sent to participants by mail (the video and in-person component were not included); still results were promising with the intervention group showing higher knowledge and the desired behavioral change of more walking away when crying was unsoothable (Fujiwara et al. 2012). Prior to the larger study in British Columbia, a randomized, controlled trial of POPC was done in Vancouver to assess the effectiveness of the educational materials on knowledge and responses to crying, which found that knowledge improved in the 
intervention group compared with the controls, but responses to crying were similar in the two groups (Barr et al. 2009). A non-experimental posttest-only evaluation study was implemented in the Midwestern USA and found that the program was wellreceived by new mothers and increased knowledge, further supporting feasibility and broader dissemination and implementation of the programming (Reese et al. 2014). A new study in the United Kingdom tried a different outcome-measuring caregiver frustration with crying in groups receiving POPC or standard discharge information. While the POPC group did not show a difference in caregiver frustration with crying, they did have significantly greater knowledge of AHT compared with the standard discharge information group (Groisberg et al. 2020).

This initiative may be the most suited to adapt to the current pandemic context. It has been shown to be low-cost and cost-effective even in wide, universal dissemination. Educational materials can be distributed to parents via mail, email, or delivered over a virtual platform for those who have access to such platforms. Utilizing technology to improve access to services and support systems already in place will be critically important as this pandemic continues and beyond (Weiner et al. 2020).

\section{Conclusions}

The COVID-19 pandemic has brought to the forefront profound structural inequalities that exist in the USA and elsewhere around the world, many of which affect how communities are experiencing child maltreatment. We have emphasized the importance of economic and social stressors including structural racism and economic devastation and the critical need to attend to structural inequalities as contributors to the risk of child maltreatment. Children and families who reside in neighborhoods of concentrated disadvantage have cumulative risks for both child maltreatment and structural discrimination. Community-level prevention efforts such as those reviewed in this article show that prevention of child maltreatment will benefit from promoting pro-social norms about caring for children and families in need and work on building collective efficacy. Accounting for intersectionality and structural inequality and dismantling structural biases are essential. These programs have aimed to expand the responsibility for the well-being of families and children beyond the scope of the child welfare system. This expansion is especially needed in the context of the COVID-19 pandemic.

Recommendations to address challenges during the COVID-19 pandemic are coming forward, such as Wilke et al. (2020) that surveyed representatives from 87 nongovernment organizations (NGOs) across 43 countries, mostly in the Global South. These experts identified many challenges currently being faced and suggested ways their governments could do things differently, including classifying child welfare workers as essential; addressing food insecurity; providing masks, running water, learning resources, and other supplies to impoverished families; and expanding virtual communication methods including provision of trainings for families: for example, teaching families methods to create predictable routines and to do self-care (Wilke et al. 2020). The research on the impacts of quarantine also provides the field with ideas for how communities can help families to experience the shutdowns as tolerable as possible and for how to support healthcare and other essential workers (Brooks et al. 2020). A recent report from Weiner et al. (2020) recommends a broadening of 
community-based supports while leveraging technology to ensure access to these supports. An international collaboration of experts has presented an ecological framework for research, policy, and practice to counteract the pandemic's effect on child maltreatment (Katz et al. 2019). More data-driven recommendations will be forthcoming as the COVID-19 pandemic continues to change the child protection landscape across the globe. Central to the recovery will be the mobilization of community-level resources and the building back up of the social fabric that can support vulnerable children and caregivers. Part of this mobilization must also include intersectional understanding of structural inequities in child welfare and our communities and efforts to dismantle structural biases and discrimination. This update to the state of the science on community-level interventions can help guide this recovery with hope that eventually the field will be able to pick up where it left off.

Funding This particular work was not supported by a formal funding mechanism.

\section{Data Availability N/A}

\section{Compliance with Ethical Standards}

Conflicts of Interest/Competing Interests The authors have no conflicts to disclose.

Code Availability N/A

\section{References}

Abdullah, A., Emery, C. R., \& Jordan, L. P. (2020). Neighbourhood collective efficacy and protective effects on child maltreatment: a systematic literature review. Health \& Social Care in the Community, 28(6), 1863-1883.

Abramson, A. (2020). How COVID-19 may increase domestic violence and child abuse. American Psychological Association. Retrieved from https://www.apa.org/topics/covid-19/domestic-violencechild-abuse. Accessed 8 Apr 2020.

Axios. (2020). "Suffering in silence": Worries mount over drop in reported child abuse cases. Axios.

Barnhart, S., \& Maguire-Jack, K. (2016). Single mothers in their communities: the mediating role of parenting stress and depression between social cohesion, social control and child maltreatment. Children and Youth Services Review, 70, 37-45.

Barr, R. G. (2012). Preventing abusive head trauma resulting from a failure of normal interaction between infants and their caregivers. Proceedings of the National Academy of Sciences, 109(supplement 2), 17294-17301.

Barr, R. G., Barr, M., Fujiwara, T., Conway, J., Catherine, N., \& Brant, R. (2009). Do educational materials change knowledge and behaviour about crying and shaken baby syndrome? A randomized controlled trial. CMAJ, 180(7), 727-733.

Barr, R. G., Barr, M., Rajabali, F., Humphreys, C., Pike, I., Brant, R., Hlady, J., Colbourne, M., Fujiwara, T., \& Singhal, A. (2018). Eight-year outcome of implementation of abusive head trauma prevention. Child Abuse \& Neglect, 84, 106-114.

Bassett, M. T., Chen, J. T., \& Krieger, N. (2020). The unequal toll of COVID-19 mortality by age in the United States: Quantifying racial/ethnic disparities. Harv Cent Popul Dev Stud Work Pap Ser, 19.

Beaulieu, E., Rajabali, F., Zheng, A., \& Pike, I. (2019). The lifetime costs of pediatric abusive head trauma and a cost-effectiveness analysis of the Period of PURPLE Crying program in British Columbia, \&nbsp;Canada. Child Abuse \& Neglect, 97, 104133. 
Berman, J. J. (2020). Flexibility and creativity: Critical elements in prevention of child maltreatment. International Journal on Child Maltreatment: Research, Policy and Practice, 3, 163-175. https://doi. org/10.1007/s42448-020-00043-9.

Bronfenbrenner, U. (1979). The ecology of human development. Cambridge, MA: Harvard University Press. Bronfenbrenner, U. (2005). Making human beings human: Bioecological perspectives on human development. Thousand Oaks, CA: Sage Publications Inc.

Brooks, S. K., Webster, R. K., Smith, L. E., Woodland, L., Wessely, S., Greenberg, N., \& Rubin, G. J. (2020). The psychological impact of quarantine and how to reduce it: Rapid review of the evidence. The Lancet., 395, 912-920.

Brown, S. M., Doom, J. R., Lechuga-Peña, S., Watamura, S. E., \& Koppels, T. (2020). Stress and parenting during the global COVID-19 pandemic. Child Abuse \& Neglect, 104699,. https://doi.org/10.1016/j. chiabu.2020.104699.

Carr, A., Duff, H., \& Craddock, F. (2020). A systematic review of reviews of the outcome of noninstitutional child maltreatment. Trauma, Violence \& Abuse, 21(4), 828-843.

Cohen, R. I. S., \& Bosk, E. A. (2020). Vulnerable youth and the COVID-19 pandemic. Pediatrics, 146(1), e20201306. https://doi.org/10.1542/peds.2020-1306.

Conrad-Hiebner, A., \& Byram, E. (2020). The temporal impact of economic insecurity on child maltreatment: a systematic review. Trauma, Violence \& Abuse, 21(1), 157-178.

Coulton, C. J., Crampton, D. S., Irwin, M., Spilsbury, J. C., \& Korbin, J. E. (2007). How neighborhoods influence child maltreatment: a review of the literature and alternative pathways. Child Abuse \& Neglect, 31(11-12), 1117-1142.

Coulton, C. J., Richter, F. G.-C., Korbin, J., Crampton, D., \& Spilsbury, J. C. (2018). Understanding trends in neighborhood child maltreatment rates: a three-wave panel study 1990-2010. Child Abuse \& Neglect, 84, $170-181$.

De Graaf, I., Speetjens, P., Smit, F., de Wolff, M., \& Tavecchio, L. (2008). Effectiveness of the Triple PPositive Parenting Program on behavioral problems in children: a meta-analysis. Behavior Modification, 32(5), 714-735.

Dias, M. S., Smith, K., DeGuehery, K., Mazur, P., Li, V., \& Shaffer, M. L. (2005). Preventing abusive head trauma among infants and young children: a hospital-based, parent education program. Pediatrics, 115(4), e470-e477.

Drake, B., \& Jonson-Reid, M. (2011). NIS interpretations: race and the national incidence studies of child abuse and neglect. Children and Youth Services Review, 33(1), 16-20.

Drake, B., \& Jonson-Reid, M. (2014). Poverty and child maltreatment. In Handbook of child maltreatment (pp. 131-148). Springer, Dordrecht. https://doi.org/10.1007/978-94-007-7208-3_7.

Drake, B., \& Rank, M. R. (2009). The racial divide among American children in poverty: Reassessing the importance of neighborhood. Children and Youth Services Review, 31(12), 1264-1271.

Drake, B., Jolley, J. M., Lanier, P., Fluke, J., Barth, R. P., \& Jonson-Reid, M. (2011). Racial bias in child protection? A comparison of competing explanations using national data. Pediatrics, 127(3), 471-478.

Dube, S. R., Anda, R. F., Felitti, V. J., Chapman, D. P., Williamson, D. F., \& Giles, W. H. (2001). Childhood abuse, household dysfunction, and the risk of attempted suicide throughout the life span: Findings from the Adverse Childhood Experiences study. JAMA, 286(24), 3089-3096.

Ferguson, J., Craig, E. A., \& Dounavi, K. (2019). Telehealth as a model for providing behaviour analytic interventions to individuals with autism spectrum disorder: a systematic review. Journal of Autism and Developmental Disorders, 49(2), 582-616.

Finkelhor, D., Turner, H. A., Shattuck, A., \& Hamby, S. L. (2013). Violence, crime, and abuse exposure in a national sample of children and youth: an update. JAMA Pediatrics, 167(7), 614-621.

Freisthler, B., \& Maguire-Jack, K. (2015). Understanding the interplay between neighborhood structural factors, social processes, and alcohol outlets on child physical abuse. Child Maltreatment, 20(4), 268277.

Freisthler, B., Merritt, D. H., \& LaScala, E. A. (2006). Understanding the ecology of child maltreatment: a review of the literature and directions for future research. Child Maltreatment, 11(3), 263-280.

Fujiwara, T., Yamada, F., Okuyama, M., Kamimaki, I., Shikoro, N., \& Barr, R. G. (2012). Effectiveness of educational materials designed to change knowledge and behavior about crying and shaken baby syndrome: a replication of a randomized controlled trial in Japan. Child Abuse \& Neglect, 36(9), 613-620.

Goldman, P. S., van Ijzendoorn, M. H., Sonuga-Barke, E. J., Bakermans-Kranenburg, M. J., Bradford, B., Christopoulos, A., Cuthbert, C., Duchinsky, R., Fox, N. A., \& Grigoras, S. (2020). The implications of COVID-19 for the care of children living in residential institutions. The Lancet Child \& Adolescent Health, 4(6), e12. 
Greene, T., Neria, Y., \& Gross, R. (2016). Prevalence, detection and correlates of PTSD in the primary care setting: a systematic review. Journal of Clinical Psychology in Medical Settings, 23(2), 160-180.

Griffith, A. K. (2020). Parental burnout and child maltreatment during the COVID-19 pandemic. Journal of Family Violence, 1-7,. https://doi.org/10.1007/s10896-020-00172-2.

Groisberg, S., Hashmi, S. S., \& Girardet, R. (2020). Evaluation of the Period of PURPLE Crying: an abusive head trauma prevention programme. Child Abuse Review, 29(3), 291-300.

Gross-Manos, D., Cohen, A., \& Korbin, J. E. (2020). Community change programs for children and youth atrisk: a review of lessons learned. Trauma, Violence \& Abuse, e1524838020915622. https://doi.org/10. $1177 / 1524838020915622$.

Hill, R. B. (2006). Synthesis of research on disproportionality in child welfare: an update. Casey-CSSP Alliance for Racial Equity in Child Welfare.

Hillis, S., Mercy, J., Amobi, A., \& Kress, H. (2016). Global prevalence of past-year violence against children: a systematic review and minimum estimates. Pediatrics, 137(3), e20154079.

Hoffman, J. A., \& Miller, E. A. (2020). Addressing the consequences of school closure due to COVID-19 on children's physical and mental well-being. World Medical \& Health Policy, 12(3), 300-310.

Humphreys, K. L., Myint, M. T., \& Zeanah, C. H. (2020). Increased risk for family violence during the COVID-19 pandemic. Pediatrics, 145(4), e20200982.

Johnson, L. M., Antle, B. F., \& Barbee, A. P. (2009). Addressing disproportionality and disparity in child welfare: evaluation of an anti-racism training for community service providers. Children and Youth Services Review, 31(6), 688-696.

Katz, C., McLeigh, J., \& Arieh, A. B. (2019). Reflections on the traditional role of social workers in child protection: lessons learned from the Strong Communities initiative in Israel. International Journal on Child Maltreatment: Research, Policy and Practice, 2(3), 199-210.

Kimbrough-Melton, R. J., \& Melton, G. B. (2015). "Someone will notice, and someone will care": How to build strong communities for children. Child Abuse \& Neglect, 41, 67-78.

Kobulsky, J. M., Dubowitz, H., \& Xu, Y. (2019). The global challenge of the neglect of children. Child Abuse \& Neglect, 104296. https://doi.org/10.1016/j.chiabu.2019.104296.

Lanius, R. A., Vermetten, E., \& Pain, C. (2010). The impact of early life trauma on health and disease: the hidden epidemic. Cambridge, MA: Cambridge University Press.

Lawson, M., Piel, M. H., \& Simon, M. (2020). Child maltreatment during the CoViD-19 pandemic: consequences of parental job loss on psychological and physical abuse towards children. Child Abuse \& Neglect, 104709. https://doi.org/10.1016/j.chiabu.2020.104709.

Limber, S. P., \& Hashima, P. Y. (2002). The social context: What comes naturally in child protection.

Limber, S. P., \& Kowalski, R. M. (2020). How schools often make a bad situation worse. International Journal on Child Maltreatment: Research, Policy and Practice, 3, 211-228. https://doi.org/10.1007/ s42448-020-00045-7.

Maguire-Jack, K., \& Showalter, K. (2016). The protective effect of neighborhood social cohesion in child abuse and neglect. Child Abuse \& Neglect, 52, 29-37.

Maguire-Jack, K., Cao, Y., \& Yoon, S. (2018). Racial disparities in child maltreatment: the role of social service availability. Children and Youth Services Review, 86, 49-55.

Manful, E., Abdullah, A., \& Cudjoe, E. (2019). Decision-making on child neglect: Ghanaian social workers' views and experiences. International Journal on Child Maltreatment: Research, Policy and Practice, 3, 271-285. https://doi.org/10.1007/s42448-019-00041-6.

McDonell, J. R., Ben-Arieh, A., \& Melton, G. B. (2015). Strong Communities for Children: results of a multiyear community-based initiative to protect children from harm. Child Abuse \& Neglect, 41, 79-96.

McLeigh, J. D., McDonell, J. R., \& Melton, G. B. (2015). Community differences in the implementation of Strong Communities for Children. Child Abuse \& Neglect, 41, 97-112.

McLeigh, J. D., McDonell, J. R., \& Lavenda, O. (2018). Neighborhood poverty and child abuse and neglect: the mediating role of social cohesion. Children and Youth Services Review, 93, 154-160.

McLeigh, J. D., Cole, D., Grate, P., \& Melton, G. (2020). One person can make a difference: stories of strong communities and their outreach workers. In Good neighbors: Safe and humane communities for children and families. Dordrecht: Springer.

McLeroy, K. R., Norton, B. L., Kegler, M. C., Burdine, J. N., \& Sumaya, C. V. (2003). Community-based interventions. American Journal of Public Health., 93(4), 529-533. https://doi.org/10.2105/ajph.93.4. 529.

Melton, G. B., \& McLeigh, J. D. (2020). The nature, logic, and significance of strong communities for children. International Journal on Child Maltreatment: Research, Policy, and Practice, 3, 125-161. https://doi.org/10.1007/s42448-020-00050-w. 
Molnar B.E., Beardslee W.R. (2014) Community-level prevention of child maltreatment. In: Korbin J., Krugman R. (eds) Handbook of Child Maltreatment. Child maltreatment (Contemporary Issues in Research and Policy), vol 2. Springer, Dordrecht. https://doi.org/10.1007/978-94-007-7208-3_15.

Molnar, B. E., Berkman, L. F., \& Buka, S. L. (2001a). Psychopathology, childhood sexual abuse and other childhood adversities: Relative links to subsequent suicidal behaviour in the US. Psychological Medicine, 31(6), 965-977.

Molnar, B. E., Buka, S. L., \& Kessler, R. C. (2001b). Child sexual abuse and subsequent psychopathology: results from the National Comorbidity Survey. American Journal of Public Health, 91(5), 753.

Molnar, B. E., Buka, S. L., Brennan, R. T., Holton, J. K., \& Earls, F. (2003). A multilevel study of neighborhoods and parent-to-child physical aggression: results from the Project on Human Development in Chicago Neighborhoods. Child Maltreatment, 8(2), 84-97.

Molnar, B. E., Beatriz, E. D., \& Beardslee, W. R. (2016a). Community-level approaches to child maltreatment prevention. Trauma, Violence \& Abuse, 17(4), 387-397.

Molnar, B. E., Goerge, R. M., Gilsanz, P., Hill, A., Subramanian, S., Holton, J. K., Duncan, D. T., Beatriz, E. D., \& Beardslee, W. R. (2016b). Neighborhood-level social processes and substantiated cases of child maltreatment. Child Abuse \& Neglect, 51, 41-53.

Morris, M. C., Marco, M., Maguire-Jack, K., Kouros, C. D., Im, W., White, C., Bailey, B., Rao, U., \& Garber, J. (2019). County-level socioeconomic and crime risk factors for substantiated child abuse and neglect. Child Abuse \& Neglect, 90, 127-138.

Nadan, Y., Spilsbury, J. C., \& Korbin, J. E. (2015). Culture and context in understanding child maltreatment: Contributions of intersectionality and neighborhood-based research. Child Abuse \& Neglect, 41, 40-48.

Nay, O. (2020). Can a virus undermine human rights? The Lancet Public Health, 5(5), e238-e239.

Neely, L., Rispoli, M., Gerow, S., Hong, E. R., \& Hagan-Burke, S. (2017). Fidelity outcomes for autismfocused interventionists coached via telepractice: a systematic literature review. Journal of Developmental and Physical Disabilities, 29(6), 849-874.

Norman, R. E., Byambaa, M., De, R., Butchart, A., Scott, J., \& Vos, T. (2012). The long-term health consequences of child physical abuse, emotional abuse, and neglect: a systematic review and metaanalysis. PLoS Medicine, 9(11). https://doi.org/10.1371/journal.pmed.1001349.

Nowak, C., \& Heinrichs, N. (2008). A comprehensive meta-analysis of Triple P-Positive Parenting Program using hierarchical linear modeling: effectiveness and moderating variables. Clinical Child and Family Psychology Review, 11(3), 114-144.

Peterson, C., Florence, C., \& Klevens, J. (2018). The economic burden of child maltreatment in the United States, 2015. Child Abuse \& Neglect, 86, 178-183.

Phelps, C., \& Sperry, L. L. (2020). Children and the COVID-19 pandemic. Psychological Trauma Theory Research Practice and Policy, 12(S1), S73.

Putnam, R. D. (2000a). Bowling alone: America's declining social capital. Culture and politics (pp. 223-234). New York, NY: Palgrave Macmillan.

Putnam, R. D. (2000b). Bowling alone: The collapse and revival of American community. Simon and schuster.

Rapoport, E., Reisert, H., Schoeman, E., \& Adesman, A. (2020). Reporting of child maltreatment during the SARS-CoV-2 pandemic in New York City from march to May 2020. Child Abuse \& Neglect, 104719,. https://doi.org/10.1016/j.chiabu.2020.104719.

Reese, L. S., Heiden, E. O., Kim, K. Q., \& Yang, J. (2014). Evaluation of Period of PURPLE Crying, an abusive head trauma prevention program. Journal of Obstetric, Gynecologic \& Neonatal Nursing, 43(6), $752-761$.

Runyan, D. K., Hennink-Kaminski, H. J., Zolotor, A. J., Barr, R. G., Murphy, R. A., Barr, M., et al. (2009). Designing and testing a shaken baby syndrome prevention program-The Period of PURPLE Crying: Keeping babies safe in North Carolina. Social Marketing Quarterly, 15(4), 2-24.

Sanders, M. R. (2012). Development, evaluation, and multinational dissemination of the Triple P-Positive Parenting Program. Annual Review of Clinical Psychology, 8, 345-379.

Sanders, M. R., Turner, K. M., \& Markie-Dadds, C. (2002). The development and dissemination of the Triple $\mathrm{P}$-Positive Parenting Program: a multilevel, evidence-based system of parenting and family support. Prevention Science, 3(3), 173-189.

Sanders, M. R., Kirby, J. N., Tellegen, C. L., \& Day, J. J. (2014). The Triple P-Positive Parenting Program: a systematic review and meta-analysis of a multi-level system of parenting support. Clinical Psychology Review, 34(4), 337-357.

Schieltz, K. M., \& Wacker, D. P. (2020). Functional assessment and function-based treatment delivered via telehealth: a brief summary. Journal of Applied Behavior Analysis, 53(3), 1242-1258. 
Schneider, W., Waldfogel, J., \& Brooks-Gunn, J. (2017). The great recession and risk for child abuse and neglect. Children and Youth Services Review, 72, 71-81.

Schwab-Reese, L. M., Drury, I., Allan, H., \& Matz, K. (2020). Oh, this is actually okay: Understanding how one state child welfare training system adapted to the COVID-19 pandemic. Child Abuse and Neglect, 104697. https://doi.org/10.1016/j.chiabu.2020.104697.

Sedlak, A. J., Mettenburg, J., Basena, M., Peta, I., McPherson, K., \& Greene, A. (2010). Fourth national incidence study of child abuse and neglect (NIS-4). Washington, DC: US Department of Health and Human Services, 9, 2010.

Sprague, C. M., Kia-Keating, M., Felix, E., Afifi, T., Reyes, G., \& Afifi, W. (2015). Youth psychosocial adjustment following wildfire: the role of family resilience, emotional support, and concrete support. Child \& Youth Care Forum, 44, 433-450.

Stephens, A., Kaltner, M., \& Liley, W. (2014). Infant abusive head trauma prevention: acceptability of the Period of PURPLE Crying® program in far North Queensland, Australia. Rural and Remote Health, 14, $1-6$.

Stout, M. (2020). Reports of child abuse and neglect are plummeting across New England: That's not a good thing. Boston Globe(April 9). Retrieved August 2, 2020.

Thompson, R. A. (2015). Social support and child protection: lessons learned and learning. Child Abuse \& Neglect, 41, 19-29.

Tomlinson, S. R., Gore, N., \& McGill, P. (2018). Training individuals to implement applied behavior analytic procedures via telehealth: a systematic review of the literature. Journal of Behavioral Education, 27(2), $172-222$.

Unholz-Bowden, E., McComas, J. J., McMaster, K. L., Girtler, S. N., Kolb, R. L., \& Shipchandler, A. (2020). Caregiver training via telehealth on behavioral procedures: a systematic review. Journal of Behavioral Education, 29(2), 246-281.

Van Dijken, M. W., Stams, G. J. J., \& De Winter, M. (2016). Can community-based interventions prevent child maltreatment? Children and Youth Services Review, 61, 149-158.

Venkatraman, S. (2020). Experts fear child abuse will increase with coronavirus isolation. $N B C$ News(March 27). Retrieved August 2, 2020.

Walsh, K., Blaustein, M., Knight, W. G., Spinazzola, J., \& Van Der Kolk, B. A. (2007). Resiliency factors in the relation between childhood sexual abuse and adulthood sexual assault in college-age women. Journal of Child Sexual Abuse, 16(1), 1-17.

Watt, T., \& Kim, S. (2019). Race/ethnicity and foster youth outcomes: an examination of disproportionality using the national youth in transition database. Children and Youth Services Review, 102, 251-258.

Weiner, D., Heaton, L., Stiehl, M., Chor, B., Kim, K., Heisler, K., Foltz, R., \& Farrell, A. (2020). COVID-19 and child welfare: Using data to understand trends in maltreatment and response. (Chapin Hall issue brief:, Issue. https://www.chapinhall.org/research/covid-19-and-child-welfare/. Accessed 15 Nov 2020.

Wilke, N. G., Howard, A. H., \& Pop, D. (2020). Data-informed recommendations for services providers working with vulnerable children and families during the COVID-19 pandemic. Child Abuse \& Neglect, 104642. https://doi.org/10.1016/j.chiabu.2020.104642.

Zolotor, A. J., Runyan, D. K., Shanahan, M., Durrance, C. P., Nocera, M., Sullivan, K., Klevens, J., Murphy, R., Barr, M., \& Barr, R. G. (2015). Effectiveness of a statewide abusive head trauma prevention program in North Carolina. JAMA Pediatrics, 169(12), 1126-1131.

Publisher's Note Springer Nature remains neutral with regard to jurisdictional claims in published maps and institutional affiliations. 